\title{
Gastric metaplasia and Helicobacter pylori infection
}

\author{
L A Noach, T M Rolf, N B Bosma, M P Schwartz, J Oosting, E A J Rauws, G N J Tytgat
}

\begin{abstract}
Duodenal and antral mucosal biopsy specimens were obtained from 139 patients with dyspeptic complaints to study the prevalence and extent of gastric metaplasia in the duodenal bulb in relation to Helicobacter pylori ( $H$ pylori) infection and duodenal ulcer disease. On logistic regression, the presence and extent of gastric metaplasia was not significantly associated with $H$ pylori infection. The prevalence of gastric metaplasia, however, was found to be higher in patients with current or past evidence of duodenal ulcer disease in comparison with subjects with functional dyspepsia $(p=0.01)$. A follow up study on 22 patients before and at least one year after eradication of $\boldsymbol{H}$ pylori showed that the mean extent of gastric metaplasia did not change significantly after eradication and did not differ when compared with 21 patients with persisting infection. It is concluded that the unchanged gastric acid output after eradication of $H$ pylori is a more important factor in the development of gastric metaplasia than the $\boldsymbol{H}$ pylori related inflammatory process.

(Gut 1993; 34: 1510-1514)
\end{abstract}

Gastric metaplasia or the appearance of patches of gastric type mucous cells interspersed between the duodenal epithelial cells, is a common finding in biopsy specimens from patients with duodenitis and duodenal ulcer disease. ${ }^{1-3}$ It may also be seen in healthy subjects, but usually to a more limited extent. ${ }^{4}$ Gastric metaplasia is considered to be an acquired change of the surface epithelium. In contrast, gastric heterotopia represents a presumably congenital misplacement of fully developed gastric mucosa, including chief cells and parietal cells. Heterotopia is less common than gastric metaplasia and not associated with duodenal inflammation or ulceration. ${ }^{15}$

It is assumed that gastric metaplasia arises from the necks of Brunner's glands and is the result of a persistently high concentration of acidity in the duodenal bulb. As such, it can be seen as an adaptive defence response to adverse conditions. Experimental and human studies support this hypothesis. ${ }^{16-10}$ But gastric metaplasia may also develop as a non-specific response to mucosal injury not associated with acid peptic damage."

Wyatt et al found gastric metaplasia to be more extensive in patients with Helicobacter pylori ( $H$ pylori) associated gastritis than in patients without $H$ pylori infection. "As $H$ pylori colonisation is restricted to gastric type epithelium, the presence of gastric metaplasia in the duodenum would allow $H$ pylori to colonise the duodenum and to produce active inflammation. As a result, the inflamed duodenal mucosa may then become susceptible to acid and this may ultimately lead to ulceration. Thus both $H$ pylori infection and acid induced gastric metaplasia are considered to be prerequisites for the development of duodenitis with polymorphonuclear activity and duodenal ulcer. ${ }^{12}$

It has previously been shown that the prevalence of gastric metaplasia in $H$ pylori positive duodenal ulcer patients is significantly lower after highly selective vagotomy than in patients with duodenal ulcer before operation. ' It has also been found that duodenal ulcer patients on continuous pharmacological acid suppression exhibit a lower prevalence of gastric metaplasia in comparison with intermittently treated patients. ${ }^{13}$ These findings suggest that gastric metaplasia is potentially a reversible disorder.

Eradication of $H$ pylori is accompanied by a rapid disappearance of signs of acute gastritis and a gradual resolution of chronic inflammatory changes. ${ }^{14}$ is Furthermore, many studies have shown that the naturally occurring relapse rate of duodenal ulcers is considerably reduced after eradication. ${ }^{16-18}$ There is also evidence that gastrin release returns to normal after successful treatment of $H$ pylori infection. ${ }^{19-21}$ It is as yet unknown, however, whether eradication of the organism influences the presence and extent of gastric metaplastic tissue in the duodenal bulb.

This study was designed to investigate the prevalence and distribution of gastric metaplasia in relation to $H$ pylori infection and duodenal ulceration and to examine whether a reduction in the extent and prevalence of gastric metaplasia occurs after eradication of $H$ pylori.

\section{Patients and methods}

One hundred and thirty nine adult patients with dyspeptic complaints had upper gastrointestinal endoscopy with multiple biopsies performed at defined sites in the gastric antrum and duodenal bulb. Oral informed consent was granted for all biopsies. Antral biopsy specimens were taken from the lesser and greater curvature, approximately $2 \mathrm{~cm}$ from the pylorus. Two specimens were placed in $2 \mathrm{ml}$ of saline for bacteriological examination and two specimens were fixed in $10 \%$ neutral formalin for histopathological examination. To determine the extent of gastric metaplasia, multiple biopsy specimens were collected from standardised sites of the duodenal bulb. In patients without focal abnormalities, specimens were taken from the roof, the floor, the anterior, and the posterior wall of the bulb. In patients with an ulcer crater, erosion or scar, two specimens were taken approximately $1 \mathrm{~cm}$ from the edge of the lesion and two from the opposite wall or an area clear of any macroscopically recognisable abnormality. The specimens were fixed in McDowell or Karnovsky's solution. 
Follow up endoscopies were performed during at least one year in a subgroup of 43 patients. These patients received treatment for $H$ pylori infection and returned for endoscopy to investigate either the result of treatment or for the purpose of this study. Treatment consisted of combinations of colloidal bismuth subcitrate, metronidazole, or amoxicillin, or all three.

The mean extent of gastric metaplasia in all biopsy specimens collected before eradication was compared with the extent of gastric metaplasia at least one year after eradication (group 1). In patients with persisting $H$ pylori infection (group 2) the mean extent of gastric metaplasia during the first 12 months of follow up was compared with the extent during the second year or later.

\section{HISTOLOGICAL ANALYSIS}

All antral biopsy specimens were stained with haematoxylin and eosin to detect the presence and severity of gastric inflammation and to identify $H$ pylori.

Duodenal biopsy specimens were stained with periodic acid Schiff (PAS) for the detection of metaplastic gastric epithelium. The presence and degree of duodenal inflammation were graded according to Wyatt's classification.'

Gastric metaplasia was defined as the occurrence of foci of gastric epithelial cells containing apical PAS positive neutral mucin together with the absence of a brush border. The extent of gastric metaplasia was estimated independently by two investigators as nil, $<5 \%, 5-20 \%$, $20-50 \%, 50-75 \%$, or $>75 \%$ of the epithelial surface of each biopsy specimen. After grading gastric metaplasia and counting the number of villi in each specimen, the mean extent of gastric metaplasia for all specimens taken at each session was calculated in relation to the number of villi in each specimen.

\section{STATISTICS}

Statistical analysis was performed using logistic regression analysis, two tailed $\chi^{2}$ test, the Wilcoxon signed rank sum test and the KruskalWallis test. $x$ statistics were used to determine interobserver agreement.

\section{Results}

A total of 927 duodenal biopsy specimens from 139 patients were studied ( 89 men, 50 women, aged 20 to 79 years, mean age $48 \cdot 2)$. $H$ pylori infection was proved by positive cultures or histological identification, or both in antral specimens from 113 patients. Gastric metaplasia was found in 88 of $113(78 \%) H$ pylori positive and 22 of $26(85 \%) H$ pylori negative patients.

TABLE I Prevalence of gastric metaplasia in relation to age, sex, and $\mathrm{H}$ pylori state

\begin{tabular}{llllll}
\hline & Prevalence & & & \\
\cline { 2 - 5 } Age $(y)$ & Hp +ve male & $H p+$ ve female & Hp-ve male & Hp-ve female & Total \\
\hline $20-39$ & $23 / 26$ & $8 / 8$ & $4 / 5$ & $1 / 2$ & $36 / 41(88 \%)$ \\
$40-59$ & $25 / 31$ & $16 / 23$ & $6 / 6$ & $2 / 3$ & $49 / 63(78 \%)$ \\
$>60$ & $13 / 17$ & $5 / 8$ & $3 / 4$ & $6 / 6$ & $27 / 35(77 \%)$ \\
Total & $61 / 74(82 \%)$ & $29 / 39(74 \%)$ & $13 / 15(87 \%)$ & $9 / 11(82 \%)$ & \\
\hline
\end{tabular}

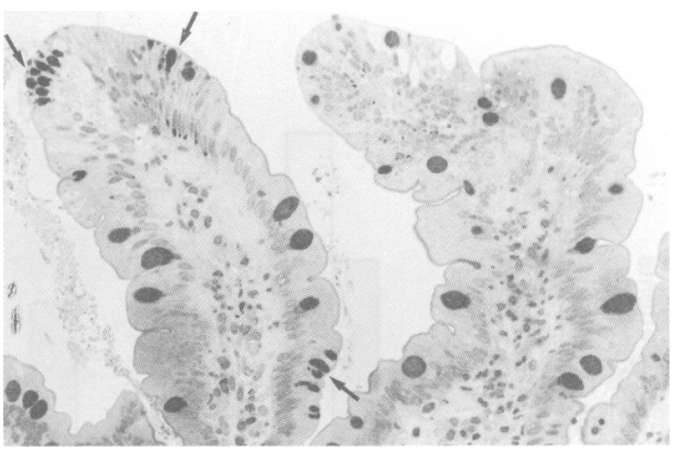

Figure 1: Duodenal biopsy specimen showing small foci of gastric metaplasia at the surface duodenal villus (arrows).

Logistic regression analysis showed no statistically significant differences in the prevalence of gastric metaplasia in different age groups, between sexes, and $H$ pylori state (Table I). The metaplastic cells usually presented in patches and did stand out clearly because of the presence of abundant PAS positive mucin in their cytoplasm. In some cases gastric metaplasia was only seen at the tips of (stunted) villi (Fig 1). In other cases the surface epithelium was more affected (Fig 2). The average extent of gastric metaplasia was calculated to be $19 \%$ in $H$ pylori positive patients and $16.2 \%$ in $H$ pylori negative patients. No relation between the extent of gastric metaplasia and the presence or absence of $H$ pylori could be shown (Mann-Whitney U test, $\mathrm{p}=0 \cdot 2)($ Fig 3$)$.

Gastric metaplasia was present in 55 of 61 ( $90 \%) H$ pylori positive patients with current or past evidence of duodenal ulceration and 31 of 44 $(70 \%)$ of patients with functional dyspepsia ( $\chi^{2}$ test, $\mathrm{p}=0.01$ ).

In 38 patients endoscopy showed focal abnormalities or signs of diffuse inflammation of the duodenal bulb. Samples taken from the edges of ulcer craters in 15 of these patients or scars in six patients contained more extensive gastric metaplasia (mean extent 19\%) in comparison with specimens from the opposite, macroscopically normal looking wall (mean extent $10 \%$ ). This difference, however, did not reach statistical significance with the signed rank sum Wilcoxon test $(p=0 \cdot 13)$. In 17 patients with an endoscopic picture of diffuse duodenitis the average extent of gastric metaplasia was $15 \%$.

Histological examination of the biopsy specimens from macroscopically abnormal tissue showed a picture of chronic duodenitis in 18 $(47 \%)$ and active duodenitis in eight $(21 \%)$ patients. Only four patients $(11 \%)$ with endo-

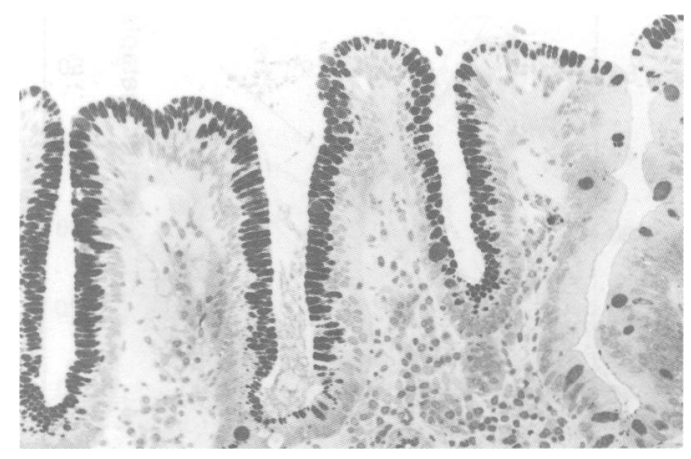

Figure 2: Duodenal biopsy specimen showing extensive area of gastric metaplasia (arrows). 


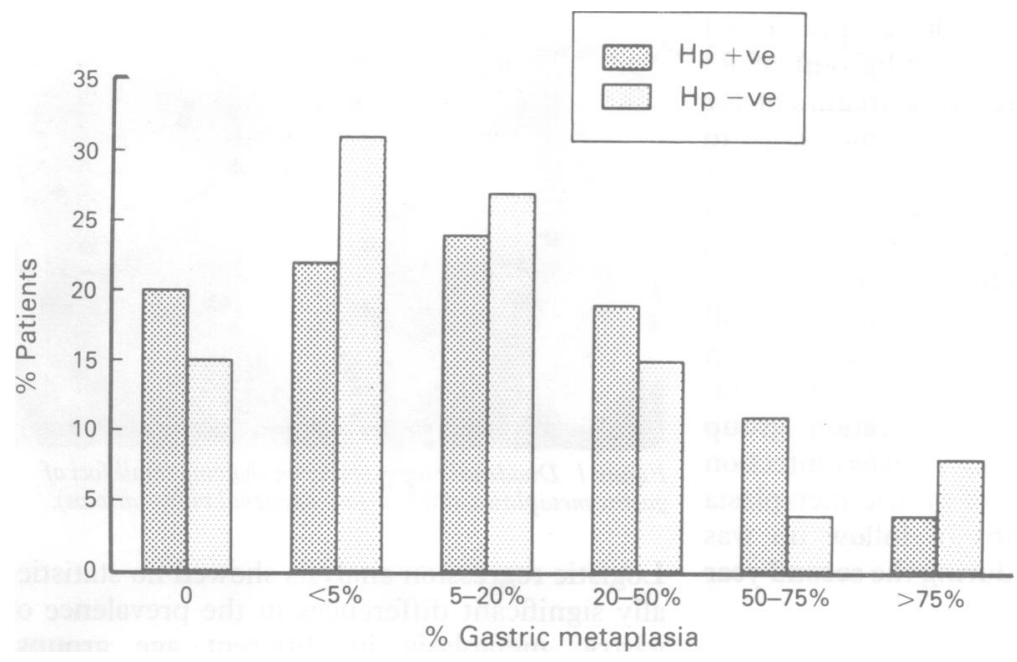

Figure 3: Distribution of different grades of gastric metaplasia in $\mathrm{H}$ pylori positive $(H p+v e)$ and negative $(\mathrm{Hp}-\mathrm{ve})$ patients. histology. scopic abnormalities had a normal duodenal

Fourteen patients had a distorted bulb without focal abnormalities. The other patients $(n=87)$ had a normal endoscopical appearance of the bulb. Microscopic examination of specimens from the second group of patients showed active duodenitis in nine patients $(10 \%)$, whereas a mononuclear infiltrate without intraepithelial neutrophils was found in 32 (37\%). Thirty five $(40 \%)$ of these patients had normal duodenal histology. Gastric metaplasia seemed to be significantly more extensive in patients with microscopic evidence of chronic or active duodenitis $(23 \%)$ in comparison with histologically normal mucosa $(13 \%)(p=0 \cdot 02)$.

A follow up study of at least 12 months was

TABLE II Characteristics of patients in follow up study.

Group 1: patients that have become $\mathrm{H}$ pylori negative; group 2: patients with persisting $\mathrm{H}$ pylori infection

Figure 4: Mean percentage of gastric metaplasia before eradication $(A 1)$ and at least 12 months after eradication (B1) of $\mathrm{H}$ pylori in patients of group 1 and during the first 12 months of follow up $(A 2)$ and at least 12 months later (B2) in patients of group 2.

\begin{tabular}{lll}
\hline & Group $I(n=22)$ & Group $2(n=21)$ \\
\hline Mean age & 45 & 49 \\
Meal/female & $14 / 8$ & $12 / 9$ \\
Duodenal ulcer disease & 11 & 10 \\
\hline
\end{tabular}

$$
\mathrm{Hp}+\mathrm{ve} \rightarrow \mathrm{Hp}-\mathrm{ve}
$$

(Group 1)

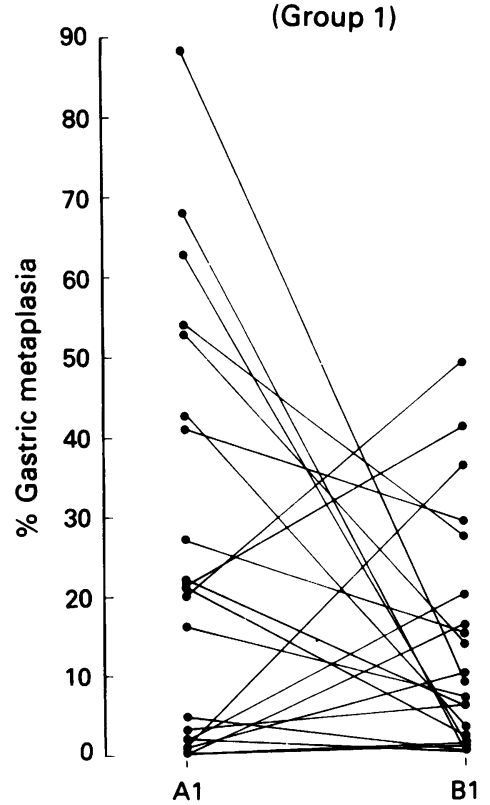

$\mathrm{Hp}+\mathrm{ve} \rightarrow \mathrm{Hp}-\mathrm{ve}$

(Group 2)

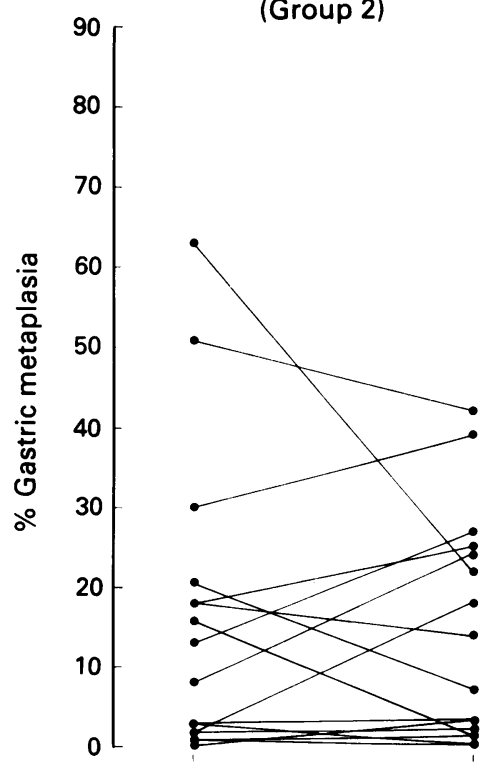

performed in 43 patients. In 22 of these patients $H$ pylori was successfully eradicated (group 1) and follow up biopsy specimens were obtained 13-60 months (median 18 months) after eradication. In the remaining 21 patients $H$ pylori was not eradicated (group 2) and these patients were followed up for 12-54 months (median 24 months). There were no significant differences with regard to age, sex, and number of patients with a history of duodenal ulcer disease between both groups (Table II).

At the start of follow up, the mean extent of gastric metaplasia was $25 \%$ (range 0 to $88 \%$ ) in group 1 and $12 \%$ (range 0 to $63 \%$ ) in group 2 . This difference, however, did not reach statistical significance (Mann-Whitney test, $p=0.08$ ). During the period of follow up, no significant decrease of the median extent of gastric metaplasia occurred in both groups (Wilcoxon rank sum test for paired data, $p=0.08$ for group 1 and $\mathrm{p}>0.5$ for group 2). Comparison of the changes in gastric metaplasia of group 1 with group 2 showed no significant difference between both groups (Mann-Whitney U test, $p=0 \cdot 3$ ) (Fig 4).

Eight patients of group 1 and seven patients of group 2 were followed up for a period of $>3$ years (mean follow up 47 (range 37-60) months for both groups). Again, the Mann-Whitney U test showed no significant change in the mean extent of gastric metaplasia in both groups $(p=0.31$ for both groups).

The mean extent of gastric metaplasia in 39 patients who were treated continuously $(>1$ year) with $\mathrm{H}_{2}$ receptor antagonists was $19 \%$ (range $0-88 \%$ ) and $15 \%$ (range $0-88 \%$ ) in 53 patients who did not take these drugs. In 38 patients who were treated intermittently $(<4$ months/year) with these drugs the mean extent was $21 \%$ (range $0-72 \%$ ). The Kruskal-Wallis test did not show a significant correlation between the extent of gastric metaplasia and the use of $\mathrm{H}_{2}$ receptor antagonists. In six patients, however, who were receiving omeprazole treatment the extent of gastric metaplasia was significantly lower than in patients using no acid reducing drugs or $\mathrm{H}_{2}$ receptor antagonist (mean $1 \%$, range $0-7 \%)(p=0.035)$. A limited extent of gastric metaplasia (of $1 \%$ in two and $16 \%$ in one patient respectively) was also found in three patients who had had highly selective vagotomy in the past. During follow up 13 patients in group 2 continued anti-secretory treatment. In these patients the extent of gastric metaplasia hardly changed (from 9 to $8 \%$ ).

\section{INTEROBSERVER AGREEMENT}

The two investigators agreed over the presence or absence of gastric metaplasia in $92 \%$ of all biopsy specimens ( $x$ value $=0.83$ ). In $79 \%$ of the biopsy specimens there was concurrence over the grading of the extent of gastric metaplasia. Only in two cases was a difference of more than one grade in the extent of gastric metaplasia found. This gave a $x$ value of 0.72 , which shows a very high level of agreement over the six categories.

Discussion

Duodenal ulcer disease has traditionally been 
TABLE III Prevalence of gastric metaplasia in asymptomatic subjects (AS), functional dyspeptic $(F D)$, and duodenal ulcer patients $(D U)$

\begin{tabular}{llll}
\hline & \multicolumn{2}{l}{ Prevalence } & \\
\cline { 2 - 4 } Author & $A S$ & $F D$ & $D U$ \\
\hline James $1964^{24}$ & & & $90 \%$ \\
Patrick et al $1974^{26}$ & & & $75 \%$ \\
Kreuning et al $1978^{4}$ & $64 \%$ & $30 \%$ & $60 \%$ \\
Greenlaw et al $1980^{25}$ & & & $39 \%$ \\
Shousha et al $1984^{30}$ & & $28 \%$ & $65 \%$ \\
Wyatt et al $1987^{1}$ & $22 \%$ & $32 \%$ & $92 \%$ \\
Fitzgibbons et al $1988^{29}$ & & & $40-90 \%$ \\
Carrick et al $1989^{2}$ & $30 \%$ & & $88 \%$ \\
Tucci et al $1990^{13}$ & & $70 \%$ & $90 \%$ \\
Offerhaus et al $1990^{27}$ & & & \\
Noach et al 1992 & & & \\
\hline
\end{tabular}

associated with excess secretion of gastric acid. The correlation, however, is incomplete implying the existence of other pathogenic factors. ${ }^{22}$ It is now widely accepted that $H$ pylori is one of the most important factors in the pathogenesis of duodenal ulcer disease. ${ }^{1523}$

Only a minority of patients infected with $H$ pylori will eventually develop a duodenal ulcer. According to previous studies, gastric metaplasia is an almost constant finding in patients with duodenal ulceration. ${ }^{12132+27}$ It is considered to be an acquired condition, as it seems to be comparatively rare in children without a history of duodenal ulceration. ${ }^{1128}$

An important problem in the detection of gastric metaplasia is its patchy distribution. Wyatt et al calculated that a single anterior biopsy detected only $63 \%$ of patients with gastric metaplasia proved by multiple biopsy. ${ }^{.1}$ This may partly explain the lower prevalence rate found in several previous studies in comparison with our results. ${ }^{11} 25$ In addition, underestimation of gastric metaplasia may occur if biopsy specimens have been collected from the distal bulb. ${ }^{29}$

Overestimation is possible in studies where biopsy specimens from the pyloroduodenal transition zone have been included..$^{1429}$ To limit sampling error, we took multiple biopsy specimens at standardised sites. Other factors may also have contributed to the large variability in prevalence rate of gastric metaplasia as mentioned in published works. These include differences in the prevalence of duodenal ulcer disease, consumption of alcohol, and the use of anti-secretory drugs in different populations. ${ }^{130}$

In this study, the extent of gastric metaplasia was estimated independently by two investigators to limit interobserver variability. We found good agreement between the two different investigators.

In agreement with previous studies, we found that gastric metaplasia was significantly more prevalent in patients with duodenal ulcer disease than in patients with functional dyspepsia (Table III). In contrast with some of these studies, we also found a comparatively high prevalence of gastric metaplasia in the second group of patients. This discrepancy may be explained by a more sensitive method of collecting biopsy specimens and is in agreement with the results of Kreuning $e t$ al who also investigated multiple biopsy specimens from the proximal duodenum. ${ }^{+}$
Marshall et al detected gastric metaplasia at the margin of ulcers in $92 \% v 63 \%$ elsewhere in the bulb. ${ }^{3}$ In accordance with Wyatt $e t$ al we found a significant association between the extent of gastric metaplasia and microscopic signs of duodenitis.' We could not show a significant difference between the extent of gastric metaplasia at sites around ulcer craters or scars and macroscopically normal appearing mucosa. Sampling error because of an insufficient number of biopsy specimens may have been responsible for the fact that this difference did not reach significance.

It has been suggested that gastric metaplasia develops as a result of high intragastric acidity or rapid gastric emptying, or both. ${ }^{122}$ This, in association with $H$ pylori infection, allows $H$ pylori to colonise the duodenum. Duodenitis follows and this inflammation impairs mucosal defences, ultimately leading to ulceration.

That gastric metaplasia develops in response to acid hypersecretion has been found both experimentally and in human studies. ${ }^{261130}$ Additional support for an acid induced mechanism comes from the finding that gastric metaplasia is quite extensive in patients with Zollinger-Ellison syndrome. ${ }^{24}$

In contrast with one previous report, we found no evidence that the chronic use of $\mathrm{H}_{2}$ receptor antagonists influenced the extent of gastric metaplasia. ${ }^{13}$ In a limited number of patients, however, who were treated continuously with omeprazole, we found an appreciably reduced extent of gastric metaplasia.

Gastric metaplasia is probably a non-specific response to injury. Heavy alcohol consumption may also cause gastric metaplasia in humans and a similar phenomenon may occur in Crohn's disease anywhere in the gastrointestinal tract. ${ }^{3031}$ It has recently been suggested that chronic inflammation in patients with Crohn's disease as well as peptic ulceration induces buds at the bottom of gastrointestinal crypts in the mucosa adjacent to ulcers. These buds are composed of columnar cells. They produce neutral mucin and develop into a new small gland. Further studies indicate that these cells are derived of a novel cell lineage. If this theory is correct, the term 'metaplasia' is a misnomer: metaplasia implies a change from one differentiated cell type to another and not the induction of a novel cell lineage. ${ }^{31}$ After eradication of $H$ pylori, duodenal ulcers do not usually recur and the associated chronic gastritis gradually disappears. ${ }^{1+16-18}$ Several investigators have found ablation of the exaggerated gastrin release after eradication of $H$ pylori. ${ }^{19-21}$ Gastric acid output, however, is not changed by treatment of the infection..$^{192132}$ The question has been raised whether these changes result in restoration of the duodenal mucosa and disappearance of gastric epithelium from the duodenal bulb.

Although the extent of gastric metaplasia decreased during follow up of group 1 , this difference did not reach statistical significance $(p=0 \cdot 08)$. Even among subjects examined at least three years after successful treatment of $H$ pylori infection, the extent of gastric metaplasia did not change significantly. In our opinion, a more appropriate comparison con- 
cerns the changes seen during follow up in group $1 v$ the changes in group 2. As stated before, these changes were statistically indistinguishable between the groups $(p=0 \cdot 3)$. We do realise that the large variability when estimating the extent of gastric metaplasia is one of the important limitations of any endoscopic study. It may well be that because of this large variation and the comparatively small numbers of patients in this study a possible correlation between the presence of $H$ pylori and the development of gastric metaplasia could not be shown. The lack of regression of gastric metaplasia in the bulb, however, is biologically compatible with the current data on the evolution of acid secretion after eradication of $H$ pylori. ${ }^{192132}$ Almost all studies show that acid secretion remains at the same rate. This would show that acid secretion is of superior importance compared with $H$ pylori.

So far, no prospective study has been performed to investigate the natural history of gastric metaplasia. Only in one report was it suggested that 'fundic gland metaplasia' was a transient lesion, which tended to disappear spontaneously within a few months. ${ }^{33}$ This paper, however, describes heterotopia and, although the number of biopsy specimens taken at endoscopy are not mentioned, the transient character of heterotopia may be a result of sampling error.

This study suggests that both acid induced injury and $H$ pylori infection may play a part in the pathogenesis of duodenal ulcer disease. Both factors may be part of a complex cascade of events that ultimately leads to the development of duodenal ulceration. Gastric metaplasia and $H$ pylori infection are prerequisites, but evidence exists that mucosal production of cytokines, $H$ pylori specific toxins and other, still unknown factors may all play a part in possible ulcer formation in the duodenum. ${ }^{34-36}$ As the acid secretory capacity does not change after $H$ pylori eradication, it would seem that the former is the more important determinant factor in the development of gastric metaplasia and the $H$ pylori related inflammatory process is of less importance.

1 Wyatt JI, Rathbone BJ, Dixon MF, Heatley RV. Campylobacter pyloridis and acid-induced gastric metaplasia in the pathogenesis of duodenitis. F Clin Pathol 1987; 40: 841-8.

2 Carrick J, Lee A, Hazell S, Ralston M, Daskalopoulos G. Campylobacter pylori, duodenal ulcer, and gastric metaCampylobacter pylori, duodenal ulcer, and gastric metaplasia: possible role of functional
ulcerogenesis. Gut $1989 ; 30: 790-7$.

3 Marshall BJ, Goodwin CS, Warren JR, Murray R, Blincow ED, Blackbourn SJ, et al. Prospective double-blind trial of duodenal ulcer relapse after eradication of Campylobacter pylori. Lancet 1988; ii: 1437-42.

4 Kreuning J, Bosman FT, Kuiper G, vd Wal AM, Lindeman J. Gastric and duodenal mucosa in 'healthy' individuals. $\mathcal{F C l i n}$ Pathol 1978; 31: 69-77.

5 Shousha S, Spiller RC, Parkins RA. The endoscopically abnormal duodenum in patients with dyspepsia:biopsy findings in 60 cases. Histopathology 1983; 7: 23-34.

6 Rhodes J. Experimental production of gastric epithelium in the duodenum. Gut 1964; 5: 454-8.

7 Dixon MF. Helicobacter pylori and peptic ulceration: histopathological aspects. $\mathcal{F}$ Gastroenterol Hepatol 1991; 6: 12530 .

8 Wyatt JI. Campylobacter pylori, duodenitis and duodenal ulceration. In: Rathbone BJ, Heatley RV, eds. Campylo- bacter pylori and gastroduodenal disease. Oxford: Blackwell Scientific, 1989.

9 Leung FW, Andrews RD, Miller JC, Paulsen G, Guth PH. Brunner's glands protect the overlying mucosa against acid induced injury. Gastroenterology 1987; 92: A 1502.

10 Joffe SN, Lee FD, Blumgart LH. Duodenitis. Clin Gastroenterol 1978; 7: 635-50.

11 Wyatt JI, Rathbone BJ, Sobala GM, Shallcross T, Heatley RV, Axon ATR, et al. Gastric epithelium in the duodenum: its association with Helicobacter pylori and inflammation. f Clin Pathol 1990; 43: 981-6.

12 Wyatt JI, Rathbone BJ, Dixon MF, Heatley RV, Axon ATR. Campylobacter pylori and development of duodenal ulcer [Letter]. Lancet 1988; i: 118-9.

13 Tucci A, Susi D, Bovani I. Effect of chronic acid inhibition on duodenal gastric metaplasia. Gastroenterology 1990; 98: A141.

14 Valle J, Seppala K, Sipponen P, Kosunen T. Disappearance of gastritis after eradication of Helicobacter pylori. Scand $\mathcal{F}$ Gastroenterol 1991; 26: 1057-65.

15 Rauws EAJ, Langenberg W, Houthoff HJ, Zanen HC, Tytgat GNJ. Campylobacter pyloridis-associated chronic active antral gastritis: a prospective study of its prevalence and the effects of antibacterial and anti-ulcer treatment. Gastroeffects of antibacterial and

16 Rauws EAJ, Tytgat GNJ. Eradication of Helicobacter pylori cures duodenal ulcer. Lancet 1990; i: 1233-5.

17 George LL, Borody TJ, Andrews P, Devine M, Moore-Jones $\mathrm{D}, \mathrm{W}$ alton $\mathrm{M}$, et al. Cure of duodenal ulcer after eradication of Helicobacter pylori. Med f A ust 1990; 153: 145-9.

18 Lamouliatte H, Bernard PH, Boulard A, Cayla R, de Mascarel A, Megraud F, et al. Helicobacter pylori eradication prevents duodenal ulcer relapse. Gastroenterology 1991; 100: A104

19 McColl KEL, Fullarton GM, Chittajalu R, El Nujumi AM, Macdonald AMI, Dahill SW, et al. Plasma gastrin, daytime intragastric $\mathrm{pH}$, and nocturnal acid output before and at 1 and 7 months after eradication of Helicobacter pylori in duodenal ulcer subjects. Scand $\mathcal{F}$ Gastroenterol 1991; 26: 339-46.

20 Graham DY, Opekun A, Lew GM, Evans DJ, Klein PD, Evans DG. Ablation of exaggerated meal-stimulated gastrin
release in duodenal ulcer patients after clearance of Helicorelease in duodenal ulcer patients after clearance of Helico-
bacter (Campylobacter) pylori infection. Am $\mathcal{F}$ Gastroenterol bacter (Campylo

21 Prewett EJ, Smith JTL, Nwokolo CU, Hudson M, Sawyerr AM, Pounder RE. Eradication of Helicobacter pylori abolishes 24-hour hypergastrinaemia: a prospective study in healthy subjects. Aliment Pharmacol Therap 1991; 5: 283-90.

22 Wormsley KG. The pathophysiology of duodenal ulceration. Gut 1974; 15: 59-81.

23 Marshall BJ, Armstrong JA, McGechie DB, Glancy RJ. Attempt to fulfil Koch's postulates for pyloric campylobacter. Med f Aust 1985; 142: 436-9.

24 James AH. Gastric epithelium in the duodenum. Gut 1964; 5 : 285-94.

25 Greenlaw R, Sheahan DG, DeLuca V, Miller D, Myerson D, Myerson P. Gastroduodenitis. A broader concept of peptic ulcer disease. Dig Dis Sci 1980; 25: 660-72.

26 Patrick WJA, Denham D, Forrest APM. Mucous change in the human duodenum: a light and electron microscopic study and correlation with disease and gastric acid secretion. Gut 1974; 15: 767-76.

27 Offerhaus GJA, Molyvas EN, Hoedemaeker PJ. Helicobacter pylori infection of gastric mucin cell metaplasia: the duodenum revisited. F Pathol 1990 162: 239-43.

28 Shabib S, Cutz E, Drumm B, Sherman P. Helicobacter pylori infection is associated with gastric metaplasia in the duodenum. Gastroenterology 1992; 102: A163.

29 Fitzgibbons PL, Dooley CP, Cohen H, Appleman MD Prevalence of gastric metaplasia, inflammation, and Crevalence of gastric metaplasia, inflammation, and normal population. Am $\mathcal{F}$ Clin Pathol 1988; 90: 711-4.

30 Shousha S, Barrison IG, El-Sayeed W, Khan S, Parkins RA. A study of incidence and relationship of intestinal metaplasia on gastric antrum and gastric metaplasia of duodenum in patients with non-ulcer dyspepsia. Dig Dis Sci 1984; 29 . $311-6$.

31 Wright NA, Pike C, Elia G. Induction of a novel epidermal growth factor-secreting cell lineage by mucosal ulceration in human gastrointestinal stem cells. Nature 1990; 343: 82-5.

32 Montbriand JR, Appelman HD, Cotner EK, Nostrant TT, Elta GH. Treatment of Campylobacter pylori does not alter gastric acid secretion. Am f Gastroenterol 1989; 84: 1513-6.

33 Terruzzi V. Gastric metaplasia of the duodenal bulb/a prospective endoscopic study [Letter]. Endoscopy 1987; 19: 252-3.

34 Denizot Y, Sobhani I, Rambaud JC, Lewin M, Thomas Y, Benveniste J. Paf-acether synthesis by Helicobacter pylori. But 1990; 31: 1242-5.

35 Crabtree JE, Shallcross TM, Heatley RV, Wyatt JI. Mucosal tumour necrosis factor $\alpha$ and interleukin- 6 in patients with Helicobacter pylori associated gastritis. Gut 1991; 32 . 1473-7.

36 Leunk RD, Johnson PT, David BC, Kraft WG, Morgan DR. Cytotoxic activity in broth-culture filtrates of Campylobacter pylori. F Med Microbiol 1988; 26: 93-9. 